\title{
BMJ Open Comparison of standardised mortality ratios for renal failure before and after the 2011 Great East Japan Earthquake and Tsunami: an analysis of national vital statistics
}

\author{
Rumi Tsukinoki, ${ }^{1}$ Yoshitaka Murakami, ${ }^{2}$ Miyuki Kawado, ${ }^{3}$ Shuji Hashimoto ${ }^{3}$
}

To cite: Tsukinoki R, Murakami Y, Kawado M, et al. Comparison of standardised mortality ratios for renal failure before and after the 2011 Great East Japan Earthquake and Tsunami: an analysis of national vital statistics. BMJ Open 2018;8:e023435. doi:10.1136/ bmjopen-2018-023435

- Prepublication history for this paper is available online. To view these files, please visit the journal online (http://dx.doi. org/10.1136/bmjopen-2018023435).

Received 1 May 2018 Revised 3 December 2018 Accepted 5 December 2018
Check for updates

(c) Author(s) (or their employer(s)) 2018. Re-use permitted under CC BY-NC. No commercial re-use. See rights and permissions. Published by BMJ.

${ }^{1}$ Department of Public Health Nursing, Japanese Red Cross College of Nursing, Tokyo, Japan ${ }^{2}$ Department of Medical Statistics, Toho University, Tokyo, Japan

${ }^{3}$ Department of Hygiene, Fujita Health University School of Medicine, Aichi, Japan

Correspondence to Dr Rumi Tsukinoki; rumitsukinoki@gmail.com

\section{ABSTRACT}

Objective The impact of the 2011 Great East Japan Earthquake on renal failure (RF) risk remains unclear. We examined the 1-year impact of this disaster on RF mortality.

Setting This ecological study focused on the year before and after the earthquake. The data sources were national vital statistics (2010-2012), the national census (2010) and the Basic Resident Registration (2010-2012). Participants Our study included all residents in Iwate, Miyagi and Fukushima, 1 year before and after the earthquake.

Primary and secondary outcome measures We calculated standardised mortality ratios (SMRs) for RF, chronic RF and acute RF. Postearthquake weekly SMRs were calculated using the number of RF deaths for the corresponding weeks in 2010 as a reference. The SMRs for RF were compared between the coastal and inland municipalities using kernel-weighted polynomial smoothing.

Results There were $1290 \mathrm{RF}$ deaths in the three prefectures during the year after the earthquake (chronic RF: 804 and acute RF: 236). The SMR for RF increased significantly in the first week after the earthquake in coastal areas (3.11; 95\% Cl: 1.84 to 4.37$)$, but did not increase in inland areas $(0.93 ; 95 \% \mathrm{Cl}: 0.47$ to 1.38$)$. A similar trend was observed for chronic RF (coastal: 4.0; $95 \% \mathrm{Cl}: 2.0$ to 6.0 ; inland: $1.1 ; 95 \% \mathrm{Cl}: 0.4$ to 1.7 ). SMRs for RF and chronic RF decreased over time and reached 1.0 approximately 20 weeks after the disaster. Changes in SMRs for acute RF were not apparent due to the low number of deaths.

Conclusions Mortality due to RF and chronic RF, but not acute RF, increased in coastal areas after the earthquake. Chronic RF may have been exacerbated by disasterinduced sympathetic activation and poor management of renal dysfunction. Increased hypertension and damage to essential infrastructure and medical equipment may also have increased mortality in people with kidney disease.

\section{INTRODUCTION}

Japan is the only developed country that has suffered numerous major earthquakes over
Strengths and limitations of this study

- This study is a population-based ecological study.

- National vital statistics covering all death information were used.

- It is the first study to show earthquake and tsunami have impacts on the mortality from renal failure (RF).

- Population movement was not considered.

- Number of RF deaths did not include all patients with RF due to cardiovascular deaths.

the past few decades. The Great East Japan Earthquake and Tsunami in 2011 was one such catastrophic disaster. Given the regularity of such devastating natural disasters, Japan requires large amounts of epidemiological evidence to support the establishment of a more responsive medical care system and public health strategies to cope with these events. These disasters not only directly cause injuries and death, but can also exacerbate pre-existing conditions. A disaster cardiovascular prevention network was developed and implemented to address the increased risks of cardiovascular events after the earthquake and tsunami in 2011. ${ }^{1}$ Several epidemiological studies have also reported on the impact of such disasters on cardiovascular disease. ${ }^{2-7}$ However, few studies have focused on the effects of earthquakes on renal failure $(\mathrm{RF})$ in Japan which is a key causal element of cardiovascular disease. ${ }^{89}$ These studies are generally clinical-based analyses that have reported on the relationship between earthquakes and crush syndrome which can lead to acute kidney injury. ${ }^{89}$ In addition, few largescale epidemiological studies have examined the association between earthquakes and cardiovascular disease or renal disease in Japan using national vital statistics or ambulance records which would shed light on the 


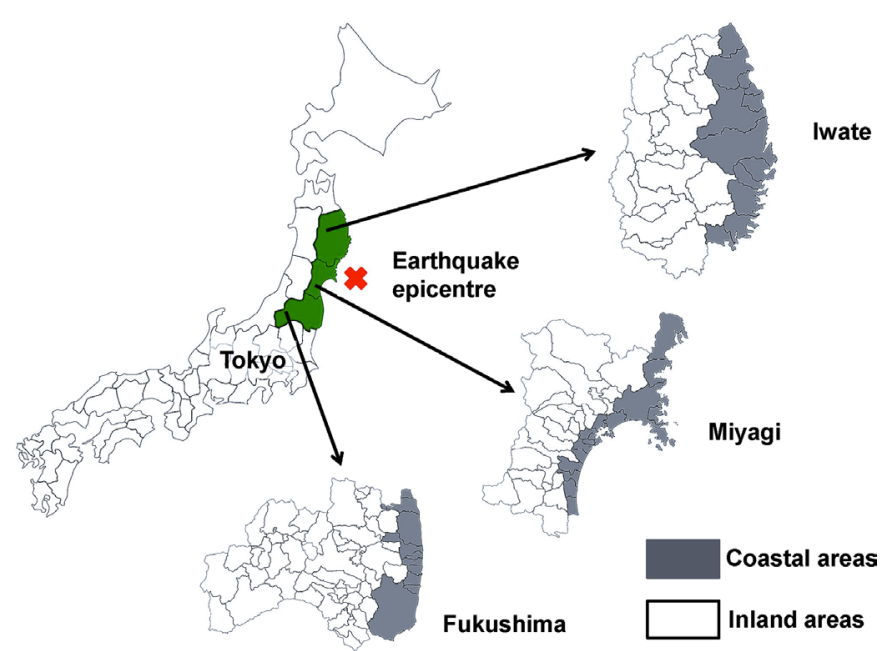

Figure 1 Map of the study area (Iwate, Miyagi and Fukushima prefectures) and the epicentre of the Great East Japan Earthquake. The shaded areas represent coastal municipalities, and the white areas represent inland municipalities.

relationship between seismic events and these diseases. ${ }^{24}$ Furthermore, there are, to our knowledge, no epidemiological studies that have reported on increases in RF mortality following an earthquake event.

The Great East Japan Earthquake, which had a magnitude of 9.0, struck the Pacific coast of Japan's North-East region on 11 March 2011. The earthquake was immediately followed by a devastating tsunami. Most of the damage caused by the tsunami was concentrated in the seacoast areas of Iwate, Miyagi and Fukushima prefectures (figure 1). ${ }^{10}$ Several clinical studies have examined the association between hypertension and chronic kidney disease after this disaster. ${ }^{11-13}$ However, the effect of the earthquake and tsunami on mortality risks associated with RF remains unclear.

To provide evidence on this relationship, we examined the impact of the 2011 Great East Japan Earthquake and Tsunami on mortality due to RF using national vital statistics.

\section{METHODS}

\section{Data sources and study population}

This is an ecological study in Japan. The study focused on the year before and after the 2011 Great East Japan Earthquake and Tsunami. The data sources were national vital statistics (2010-2012), the national census (2010) and the Basic Resident Registration (2010-2012). The National vital statistics were collected from the Ministry of Health, Labour and Welfare. The national census and the Basic Resident Registration were obtained from Ministry of Internal Affairs and Communications. In accordance with the Statistics Act in Japan and United Nations Fundamental Principles of Official Statistic, the permission for using these anonymised data were given by the Ministry of Health, Labour or Welfare and the Ministry of Internal Affairs and Communications.
We obtained data for all residents of the 131 municipalities in Iwate, Miyagi and Fukushima prefectures (total population of approximately 5.7 million) from 2010 to 2012. These three prefectures were selected as they had sustained severe damage during the disaster. The municipalities were divided into coastal $(\mathrm{n}=38)$ and inland $(\mathrm{n}=93)$ areas (figure 1$)$. Mortality data from the national vital statistics were provided by prefectural public health centres which regularly send the data to the Ministry of Health, Labour and Welfare, Japan. The collection of data by these public health centres was suspended due to the earthquake and tsunami, but the data were eventually collected and submitted by June 2011. Data on RF deaths were obtained from the respective prefectural governments for 1 year before and after the disaster (11 March 2010 to 10 March 2012). Population data were obtained from the Basic Resident Register and national census which are managed by the respective municipal governments.

\section{Outcomes}

We defined diseases of the genitourinary system using the International Classification of Diseases, 10th Revision codes (N00 to N99). These included RF (N17N19), acute RF (N17) and chronic RF (N18). Our study classification did not include earthquake encounters (X34).

\section{Statistical analysis}

We analysed sex and age-specific municipal-level populations for each week during the 2-year study period. The age was categorised into 5-year intervals from 0 to 4 to $80-84$ and $\geq 85$. All analysis was based on the estimated populations from the Basic Resident Register using a linear estimation method. ${ }^{14}$

Standardised mortality ratios (SMRs) were calculated to examine the changes in RF mortality from 1 year before the earthquake to 1 year after the earthquake with adjustments for sex and age. The weekly expected number of deaths was calculated as follows; sex and age-specific RF mortality before the earthquake ( -52 to -1 weeks; designated the subject period) was multiplied by the sex and age-specific population after the earthquake $(+1$ to +52 weeks; designated the comparison period). The SMRs were then calculated by dividing the total number of observed deaths by the expected number of deaths. The 95\% CIs of the SMRs were estimated using Poisson distributions. SMRs were calculated separately for coastal and inland municipalities. The changes of the weekly SMRs for diseases (the genitourinary system, RF, acute RF and chronic RF) in the coastal and inland municipalities were described by kernel-weighted local polynomial smoothing.

We considered $\mathrm{p}$ values below 0.05 to be statistically significant. All analyses were performed using SAS Release V.9.3 (SAS Institute) and STATA V.12.0. 
Table 1 Population characteristics and renal-related deaths in the coastal and inland areas of Iwate, Miyagi and Fukushima prefectures

\begin{tabular}{|c|c|c|}
\hline & Coastal areas & Inland areas \\
\hline Population, $\mathrm{n}$ & 1801324 & 3924653 \\
\hline \multicolumn{3}{|l|}{ Sex, n (\%) } \\
\hline Female & $925551(51.4)$ & $2023322(51.6)$ \\
\hline Male & $875773(48.6)$ & $1901331(48.4)$ \\
\hline \multicolumn{3}{|l|}{ Age, years (SD) } \\
\hline $0-14$ & $241192(13.4)$ & $525623(13.4)$ \\
\hline $15-64$ & $1123719(62.4)$ & $2455402(62.6)$ \\
\hline $65+$ & $436413(24.2)$ & $943628(24.0)$ \\
\hline \multicolumn{3}{|l|}{ All deaths, $n$} \\
\hline One-year pre-earthquake & 19357 & 41902 \\
\hline One-year post earthquake & 20443 & 44650 \\
\hline \multicolumn{3}{|l|}{ Renal-related deaths, $\mathrm{n}$} \\
\hline \multicolumn{3}{|c|}{ Diseases of the genitourinary system } \\
\hline One-year pre-earthquake & 558 & 1144 \\
\hline One-year postearthquake & 575 & 1198 \\
\hline \multicolumn{3}{|c|}{ Glomerular diseases and renal tubulointerstitial diseases } \\
\hline One-year pre-earthquake & 72 & 157 \\
\hline One-year postearthquake & 49 & 131 \\
\hline \multicolumn{3}{|l|}{ Renal failure } \\
\hline One-year pre-earthquake & 402 & 819 \\
\hline One-year postearthquake & 433 & 857 \\
\hline \multicolumn{3}{|l|}{ Chronic renal failure } \\
\hline One-year pre-earthquake & 278 & 503 \\
\hline One-year postearthquake & 288 & 523 \\
\hline \multicolumn{3}{|l|}{ Acute renal failure } \\
\hline One-year pre-earthquake & 69 & 173 \\
\hline One-year postearthquake & 62 & 175 \\
\hline
\end{tabular}

Renal failure deaths, $\mathrm{n}$

\begin{tabular}{lll} 
Iwate & & \\
One-year pre-earthquake & 80 & 251 \\
One-year postearthquake & 79 & 247 \\
Miyagi & & \\
One-year pre-earthquake & 190 & 251 \\
$\quad$ One-year postearthquake & 211 & 270 \\
Fukushima & & \\
$\quad$ One-year pre-earthquake & 132 & 317 \\
One-year postearthquake & 143 & 337 \\
\hline
\end{tabular}

\section{Patient and public involvement statement}

The public or patients were not involved in developing the research question or the outcome measures.

\section{RESULTS}

Table 1 shows the population characteristics and renal-related deaths in the coastal and inland municipalities of the three target prefectures. The study population comprised 1801324 individuals from the coastal areas and 3924653 individuals from the inland areas. The sex and age composition were similar between the coastal and inland areas. In addition, the number of all deaths (after excluding victims of the earthquake) during the year after the earthquake was similar to that of the year before the earthquake in both the coastal and inland areas. Similarly, the numbers of renal-related deaths were similar during the years before and after the earthquake in both areas. The number of deaths in the three prefectures 1 year after the earthquake was 1290, 237 and 811 for RF, acute RF and chronic RF, respectively. The numbers of RF deaths in Iwate, Miyagi and Fukushima were similar during the years before and after the earthquake in both areas.

Figures 2 and 3 show the SMRs for diseases of the genitourinary system, RF, chronic RF and acute RF in the coastal and inland areas 1 year after the earthquake. The SMR for diseases of the genitourinary system in coastal areas increased significantly in the first week after the earthquake (2.21; 95\% CI: 1.32 to $3.09, \mathrm{p}<0.001)$; in contrast, the corresponding SMR in the inland areas did not increase during this period $(0.93 ; 95 \%$ CI: 0.53 to 1.34, $\mathrm{p}=0.847$ ). Similarly, the SMR for RF in coastal areas increased significantly and substantially in the first week after the earthquake (3.11; 95\% CI: 1.84 to $4.37, \mathrm{p}<0.001)$; in contrast, the corresponding SMR in the inland areas did not increase during this period $(0.93 ; 95 \%$ CI: 0.47 to $1.38, \mathrm{p}=0.856$ ). We noted a similar trend in the SMRs for chronic RF (coastal: 4.0; 95\% CI: 2.0 to 6.0; $\mathrm{p}<0.001$; inland: 1.1 ; $95 \%$ CI: 0.4 to $1.7, \mathrm{p}=0.966)$. The SMRs for $\mathrm{RF}$ and chronic RF decreased over time and reached 1.0 approximately 20 weeks after the earthquake. Although SMRs for acute RF was statistically unstable because of few numbers of deaths, the SMR for acute RF in both coastal and inland areas did not show increasing trends after the earthquake.

\section{DISCUSSION}

In this analysis of national vital statistics, national census data and resident registry data, our results showed that SMRs for RF and chronic RF (but not acute RF) had increased in coastal areas between 1 and 20 weeks after the 2011 Great East Japan Earthquake and Tsunami. This is the first study to demonstrate the impact of an earthquake and tsunami on death associated with RF and chronic RF in a large population.

These findings suggest that chronic RF was exacerbated by poor RF management resulting from damage to essential infrastructure and medical equipment by the earthquake and tsunami, particularly in the coastal areas. Some studies reported that the dialysis facilities and equipment damage and electoral and water system (eg, the reverse osmosis) were damaged by the Great East Japan earthquake. ${ }^{15} 16$ Maintenance haemodialysis was continued immediately even after the earthquake. But the duration of haemodialysis was shortened by $0.5-1$ hour owing to 

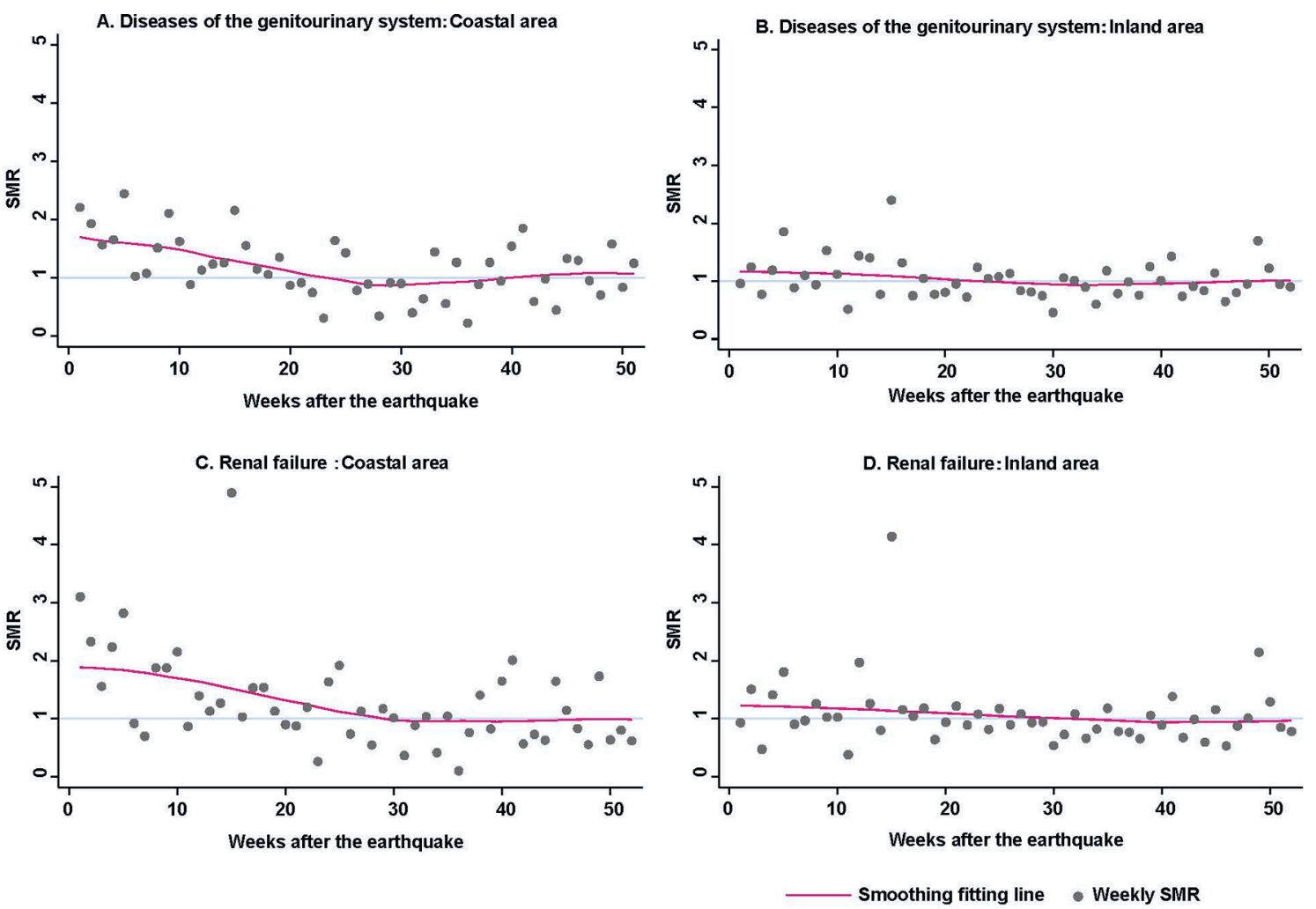

Figure 2 Weekly standardised mortality ratios (SMRs) for diseases of the genitourinary system, renal failure in coastal and inland areas 1 year after the earthquake. SMRs for diseases of the genitourinary system in coastal (A) and inland (B) areas, for renal failure in coastal (C) and inland (D) areas. The x-axes of the plots indicate the number of weeks for 1 year after the earthquake and tsunami (11 March 2011 to 10 March 2012). The grey circles represent weekly SMRs. The pink lines represent the polynomial smooth-fitted lines from the weekly SMRs. The weekly SMRs were calculated for 1 year after the earthquake using a smooth-fitted line by kernel-weighted local polynomial smoothing.

a shortage of materials for the haemodialysis, especially among coastal areas of three prefectures. ${ }^{1516}$

Chronic RF may also have been aggravated by psychological stress due to the disaster. Previous studies have shown that sympathetic nervous system overactivity parallels the severity of chronic RF after a natural disaster. ${ }^{17-19}$ Other studies have reported that patients with pre-existing chronic RF experienced elevated blood pressure after an earthquake due to increased stress levels triggered by the sympathetic nervous system, thereby further exacerbating their condition. ${ }^{611-13}$ Also, patients with chronic kidney disease and microalbuminuria experienced gradually worsening symptoms for a month after an earthquake. ${ }^{611-13}$ Tanaka et al suggested that the increased blood pressure following the Great East Japan Earthquake and Tsunami returned to the baseline level after 5-7 weeks in patients with chronic kidney disease and patients on regular dialysis. ${ }^{11}$ Especially, The Fukushima Health Management Survey also reported metabolic factors (body mass index, glucose and lipid metabolism and liver function) became worse in the evacuee group than in the non-evacuees in the low-risk group for chronic kidney disease complications. ${ }^{20}$ The difference between these two groups might be related to the lifestyle change and the environment before and after the evacuation. Chronic stress and insufficient sleep due to a life as the evacuee in unfavourable conditions could lead to become exacerbated blood pressure, metabolic factor and renal function. ${ }^{20}{ }^{21}$ In the present study, the explanation of increased SMR for chronic RF in coastal region might be same as those of the previous study. ${ }^{20}{ }^{21}$

Increased SMRs for acute RF were not observed which may have been due to the rarity of crush syndrome. After the tsunami in 2011, 92.4\% of deaths were due to drowning, whereas only $4.4 \%$ of deaths were due to crush injuries. ${ }^{10}$ In contrast, approximately $83.3 \%$ of all deaths were attributable to crush injuries in the HanshinAwaji earthquake which occurred in the Hanshin region of Japan in $1995 .{ }^{9}$ Crush-related acute RF is reported to be one of the few life-threatening conditions that can be reversed after an earthquake. ${ }^{8922-24}$ Oda et al retrospectively reviewed the medical records of 6107 patients hospitalised in 95 hospitals after the Hanshin-Awaji earthquake, and identified 372 patients with crush syndrome; among these, a total of 50 patients $(13.4 \%)$ had died. ${ }^{9}$ The main causes of death within 5 days after that earthquake were hypovolaemia and hyperkalaemia. ${ }^{9}$

Although the findings of the present study have important implications in public health and disaster medicine, there are limitations that should be noted. First, all coastal municipalities were considered earthquake and tsunami-impacted areas in the analysis. 

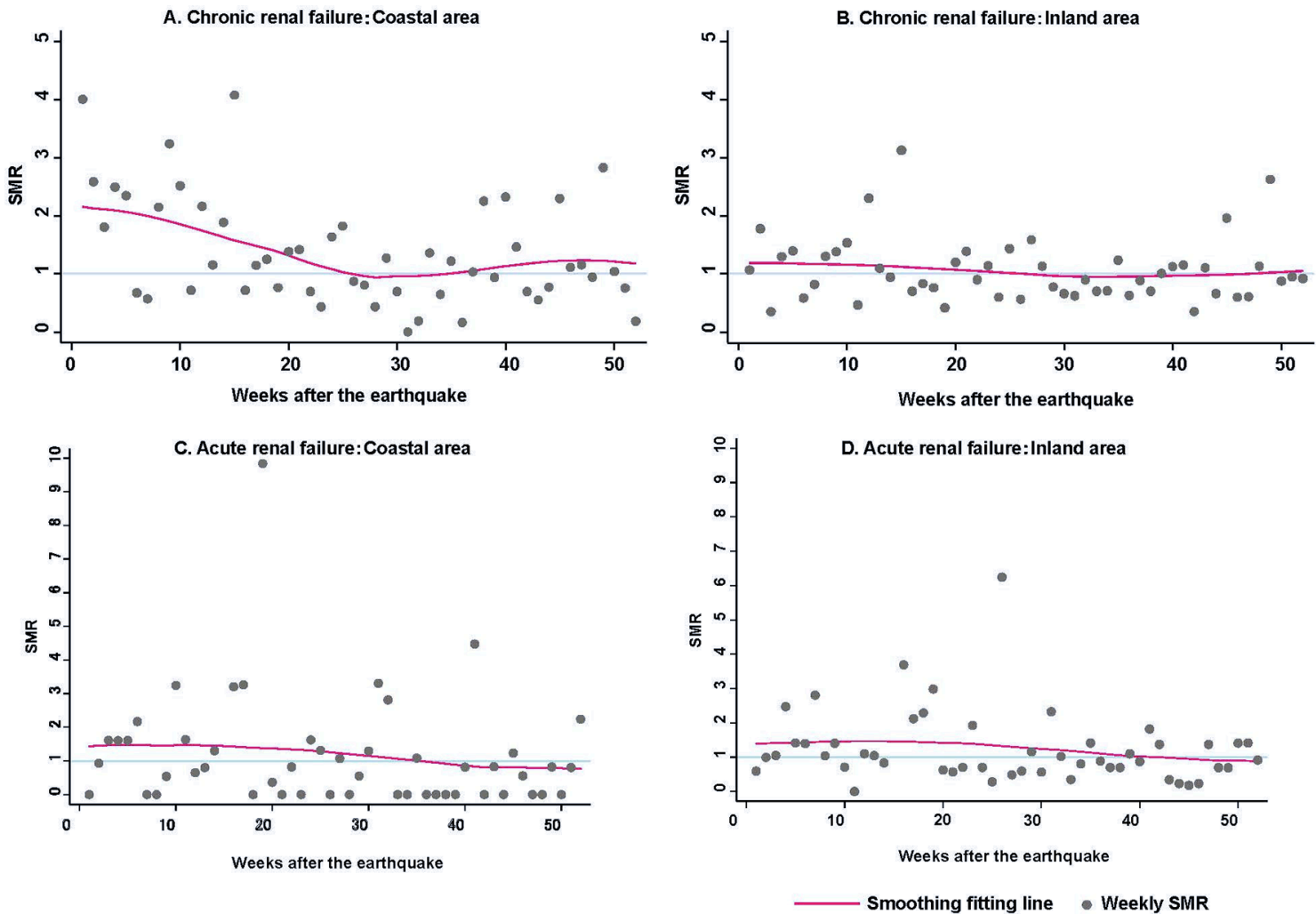

Figure 3 Weekly standardised mortality ratios (SMRs) for diseases of the chronic renal failure and acute renal failure in coastal and inland areas 1 year after the earthquake. SMRs for chronic renal failure in coastal (A) and inland (B) areas, and for acute renal failure in coastal $(C)$ and inland $(D)$ areas. The $x$-axes of the plots indicate the number of weeks for 1 year after the earthquake and tsunami (11 March 2011 to 10 March 2012). The grey circles represent weekly SMRs. The pink lines represent the polynomial smooth-fitted lines from the weekly SMRs. The weekly SMRs were calculated for 1 year after the earthquake using a smooth-fitted line by kernel-weighted local polynomial smoothing.

However, it is difficult to accurately classify municipalities based on tsunami damage, and some coastal municipalities may include undamaged areas. Second, population movements were not considered. A portion of residents would have been evacuated from coastal municipalities to inland municipalities or to the inland areas of the same municipalities. Third, patients with RF are likely to develop cardiovascular event after the disaster. ${ }^{16}$ Number of RF deaths did not include all patients with RF due to cardiovascular deaths. Hence, this study may underestimate the impact of RF by the earthquake. Finally, almost 400 cases of RF deaths were observed in three prefectures within a year, but the average number of weekly cases was only eight per week. This number was too low to show prefecture-specific results in the analysis. Because of this limitation, we only showed the results of RF mortality in both coastal and inland areas of three prefectures (Miyagi, Iwate and Fukushima) after the Great East Japan Earthquake. All these limitations may have led to an underestimation of the tsunami's effects on RF mortality.

In conclusion, this analysis is - to the best of our knowledge - the first comprehensive epidemiological study to examine the impact of the 2011 Great East Japan Earthquake and Tsunami on RF mortality using national vital statistics. Our findings indicate that mortality associated with RF and chronic RF had increased in coastal areas until approximately 20 weeks after the disaster. Further large-scale epidemiological studies should carefully assess the impact of various disasters on renal-related conditions and deaths. Due to the high frequency of earthquakes and other natural disasters in Japan, our results emphasise the need to develop public health strategies from the first week to approximately 20 weeks for effective and efficient disaster managements for RF such as the control of dialysis facilities, medicine, cardiovascular risk factors, lifestyle and stress in the wake of these disasters, particularly among evacuees with RF.

Contributors RT, YM, MK and SH conceived the study, planned the analytic approach and performed the analysis. RT and YM interpreted the results and drafted the manuscript. MK and SH commented on and edited further drafts. All authors read and approved the final manuscript.

Funding This work was supported by Health Sciences Research Grants (H24-Toukei-Ippan-006, H25-Kenki-Shitei-002 [fukkou]) from the Ministry of Health, Labour and Welfare of Japan and a Grant-in- Aid for Scientific Research (C: JP 17K12555) from Japan Society for the Promotion of Science.

Competing interests None declared.

Patient consent for publication Not required.

Ethics approval Ethics Committee/Institutional Review Board approval did not need to obtain, because this study use data from the national vital statistics without individual data. The Ministry of Health, Labour and Welfare of Japan approved this study.

Provenance and peer review Not commissioned; externally peer reviewed. 
Data sharing statement No additional data available.

Open access This is an open access article distributed in accordance with the Creative Commons Attribution Non Commercial (CC BY-NC 4.0) license, which permits others to distribute, remix, adapt, build upon this work non-commercially, and license their derivative works on different terms, provided the original work is properly cited, appropriate credit is given, any changes made indicated, and the use is non-commercial. See: http://creativecommons.org/licenses/by-nc/4.0/.

\section{REFERENCES}

1. Kario K, Nishizawa M, Hoshide S, et al. Development of a disaster cardiovascular prevention network. Lancet 2011;378:1125-7.

2. Ogawa K, Tsuji I, Shiono K, et al. Increased acute myocardial infarction mortality following the 1995 Great Hanshin-Awaji earthquake in Japan. Int J Epidemiol 2000;29:449-55.

3. Nakagawa I, Nakamura K, Oyama M, et al. Long-term effects of the Niigata-Chuetsu earthquake in Japan on acute myocardial infarction mortality: an analysis of death certificate data. Heart 2009;95:2009-13.

4. Aoki T, Fukumoto Y, Yasuda S, et al. The Great East Japan Earthquake disaster and cardiovascular diseases. Eur Heart $J$ 2012;33:2796-803.

5. Morita T, Nomura S, Tsubokura M, et al. Excess mortality due to indirect health effects of the 2011 triple disaster in Fukushima, Japan: a retrospective observational study. J Epidemiol Community Health 2017;71:974-80.

6. Kario K, McEwen BS, Pickering TG. Disasters and the heart: a review of the effects of earthquake-induced stress on cardiovascular disease. Hypertens Res 2003;26:355-67.

7. Kario K, Matsuo T, Kobayashi H, et al. Earthquake-induced potentiation of acute risk factors in hypertensive elderly patients: possible triggering of cardiovascular events after a major earthquake. J Am Coll Cardiol 1997;29:926-33.

8. Tanaka H, Oda J, Iwai A, et al. Morbidity and mortality of hospitalized patients after the 1995 Hanshin-Awaji earthquake. Am J Emerg Med 1999;17:186-91.

9. Oda J, Tanaka H, Yoshioka T, et al. Analysis of 372 patients with crush syndrome caused by the Hanshin-Awaji earthquake. $J$ Trauma 1997:42:470-6.

10. Agency NP. Police activities and the Great East Japan Earthquake. The White Paper on Police 2012;2011:1-9.
11. Tanaka K, Nakayama M, Tani Y, et al. The great East Japan earthquake: blood pressure control in patients with chronic kidney disease. Am J Hypertens 2012;25:951-4.

12. Watanabe K, Tani $\mathrm{Y}$, Tanaka K, et al. Acute changes in home blood pressure after the Great East Japan Earthquake among patients with chronic kidney disease in Fukushima City. Clin Exp Nephrol 2013;17:718-24.

13. Tani Y, Nakayama M, Tanaka K, et al. Blood pressure elevation in hemodialysis patients after the Great East Japan Earthquake. Hypertens Res 2014;37:139-44.

14. Shibata Y, Ojima T, Tomata Y, et al. Characteristics of pneumonia deaths after an earthquake and tsunami: an ecological study of 5.7 million participants in 131 municipalities, Japan. BMJ Open 2016;6:e009190.

15. Haga N, Hata J, Yabe M, et al. The great East Japan earthquake affected the laboratory findings of hemodialysis patients in Fukushima. BMC Nephrol 2013;14:239.

16. Masakane I, Akatsuka T, Yamakawa T, et al. Survey of dialysis therapy during the Great East Japan Earthquake Disaster and recommendations for dialysis therapy preparation in case of future disasters. Renal Replacement Therapy 2016;2:48.

17. Grassi G, Quarti-Trevano F, Seravalle G, et al. Early sympathetic activation in the initial clinical stages of chronic renal failure. Hypertension 2011;57:846-51.

18. Augustyniak RA, Tuncel M, Zhang W, et al. Sympathetic overactivity as a cause of hypertension in chronic renal failure. $J$ Hypertens 2002;20:3-9.

19. Converse RL, Jacobsen TN, Toto RD, et al. Sympathetic overactivity in patients with chronic renal failure. N Engl J Med 1992;327:1912-8.

20. Satoh H, Ohira T, Nagai M, et al. Prevalence of renal dysfunction among evacuees and non-evacuees after the Great East Earthquake: results from the Fukushima Health Management Survey. Intern Med 2016;55:2563-9.

21. Ohira T, Hosoya M, Yasumura S, et al. Evacuation and risk of hypertension after the Great East Japan Earthquake: the Fukushima Health Management Survey. Hypertension 2016;68:558-64.

22. Vanholder R, van der Tol A, De Smet M, et al. Earthquakes and crush syndrome casualties: lessons learned from the Kashmir disaster. Kidney Int 2007;71:17-23.

23. Vanholder R, Gibney N, Luyckx VA, et al. Renal disaster relief task force. Renal disaster relief task force in Haiti earthquake. Lancet 2010;375:1162-3.

24. Sever MS, Vanholder R, Lameire N. Management of crush-related injuries after disasters. N Engl J Med 2006;354:1052-63. 